Dhaka Univ. J. Biol. Sci. 23(2): 135-146, 2014 (July)

\title{
SPECIES TYPE AND FOREST HEALTH ASSESSMENT VIA HYPERSPECTRAL REMOTE SENSING IN THE PART OF HIMALAYAN RANGE, INDIA
}

\author{
Dharmendra Singh ${ }^{1}$, SARnAm SingH ${ }^{2}$, V.R. LeKSHMI ${ }^{3}$, SuKUmar DutTA ${ }^{4}$, \\ Nazma ${ }^{5}$, Md. Shahjahan Ali ${ }^{4}$ and Ashfaque Ahmed* \\ Ecology and Environment Laboratory, Department of Botany \\ University of Dhaka, Dhaka-1000, Bangladesh
}

Key words: Analytical spectral device, SAM, Forest health assessment

\begin{abstract}
Ground spectra using analytical spectral device were collected for dominant species in Rajpur and Mussoorie hills of Lesser Himalayas of India for mapping dominant plant species. Hyperspectral remote sensing data (EO-1) was used for classification of temperate species such as Quercus leucotrichophora, Cedrus deodara, Thuja orientalis, subtropical species like Pinus roxburghii, and tropical species such as Shorea robusta, Lantana camara, etc. using Spectral Angle Mapper. A total of 14 species were mapped along with the 4 other land use/cover classes (Agriculture, settlement, main river course, barren land). Map accuracy was 77\% assessed on the basis of 66 ground truth ground control point. The exotic species, Lantana camara was mapped in the area which has been found to be distributed from tropical to lower temperate regions and was showing impact on the health of the neighboring species which was derived from the Hyperion data. Large impact has been observed in the Shorea robusta species and its health distribution map showed $48 \%$ healthy and $52 \%$ less healthy part.
\end{abstract}

\section{Introduction}

Locating and collecting information about key stone, endemic, endangered, rare, threatened species (RET species) is utmost importance in the forestry and ecology research sector and for the species specific planning and management to ensure sustainable utilization of these natural resources. One possible approach to locate and map the species is the ground surveying which is costly, time consuming and required huge manpower ${ }^{(1)}$. The remote sensing with the collaboration of geoinformation technology is cost effective, requires less manpower, covers synoptic view of the landscape and provides timely and accurate information ${ }^{(1-4)}$. Remotely sensed information became milestone in the field of forestry and natural resource science which

*Author for correspondence: <aashfaque67@yahoo.com>. ${ }^{1}$ Forest Survey of India, Ministry of Environment and Forests, Kaulagarh Road, Dehradun 248001, India. 'Indian Institute of Remote Sensing, ISRO, Dehradun, 248001, India. ${ }^{3}$ Cochin University of Science and Technology (CUSAT), Thiruvananthapuram, Kerala, India. ${ }^{4}$ Bangladesh Space Research and Remote Sensing Organization (SPARRSO), Bangladesh. ${ }^{5}$ Local Government Engineering Department (LGED), Agargaon, Dhaka, Bangladesh. 
is a reliable method and a practical means of estimating various biophysical and biochemical vegetation variables $(5,6)$. However, a major drawback of traditional remote sensing is the use of average spectral information over broad band-widths, which results in the loss of crucial information available in specific narrow bands ${ }^{(7,8)}$.

The biological activities of deferent plant species are generally characterized by electromagnetic regions and the NIR region of the remotely sensed spectral signals of the plant species is much effective in the species discrimination(9). Pinet et al.(10) reviewed the possibilities of using imaging spectroscopy for monitoring land degradation and desertification. Hyperspectral data provides narrow band combination with contiguous spectral signature based on molecular absorption which enables us to discriminate species on the basis of their spectral response pattern(11). Carter et al.(12) had compared the ability of three sensors Thematic mapper, QuickBird and Hyperion in the discrimination of Tamarix spp. and concluded that the QuickBird is the most effective in term of accuracy. Datt( ${ }^{(13)}$ found relationship of reflectance with the gravimetric water content and equivalent water thickness (EWT) in Eucalyptus leaves. Skoupy et al.(14) studied age composition of the forest using an airborne Hyperspectral sensor AISA Eagle VNIR.

Omar(15) used WorldView-2 imagery to map the tropical vegetation and was able to identify ten species with an overall accuracy of $90 \%$. Dlamini ${ }^{(16)}$ identified two invasive alien plants, namely Lantana camara and Chromolaena odorata using new spectral bands of WorldView-2 satellite in Central Switzerland. Vyas et al.(17) evaluated the 3 deferent classifier (ANN, SAM, SVM) to classify tropical vegetation using Hyperion EO-1 data. As the information about specific species are most valuable in the structural and functional analysis of the ecosystem, their role in the atmospheric carbon sequestration, developing models those are able to relate biophysical and biochemical characteristic ${ }^{(18)}$ of the vegetation, age class determination and species level biomass mapping, information about the spectral response of the specific species in specific climatic region is needed ${ }^{(19)}$. The high spectral resolution of hyperspectral data is vital for yielding quality information like above. The present study was undertaken for the identification of the best ranges for specific species and for their functions in the part of Himalayan range.

\section{Materials and Methods}

The study area (Fig. 1) lies on the hills of Lesser Himalayas of Uttarakhand state of India. It spans from Rajput hills of Shiwalik to the Mussoorie hills and is located between $77^{\circ} 59^{\prime} 8.16^{\prime \prime}$ and $78^{\circ} 05^{\prime} 14.23^{\prime \prime} E$ longitude and $30^{\circ} 26^{\prime} 15.35^{\prime \prime}$ and $30^{\circ} 08^{\prime} 14.23^{\prime \prime} \mathrm{N}$ latitude. It covers an area of about $11,200 \mathrm{~km}^{2}$, which is a landscape dominated by of Oak forest, Shorea robusta (Sal) forest, mixed vegetation, agriculture and settlement.

Remote sensing satellite Hyperspectral data EO-1, L1R level, of Hyperion sensor were used for the mapping of dominant tree species. The data downloaded from the 
USGS (http://www.glovis.com) and saved in the ENVI standard format. This data was first de-stripped and then corrected atmospherically using FLAASH (Fast line-of-sight atmospheric analysis of spectral hypercubes) atmospheric correction model. The FLAASH algorithm support data from Non-Nadir looking sensors also. It is suitable for water vapour and aerosol retrieval and adjacency effect correction which is spatial mixing of radiance among nearby pixels.

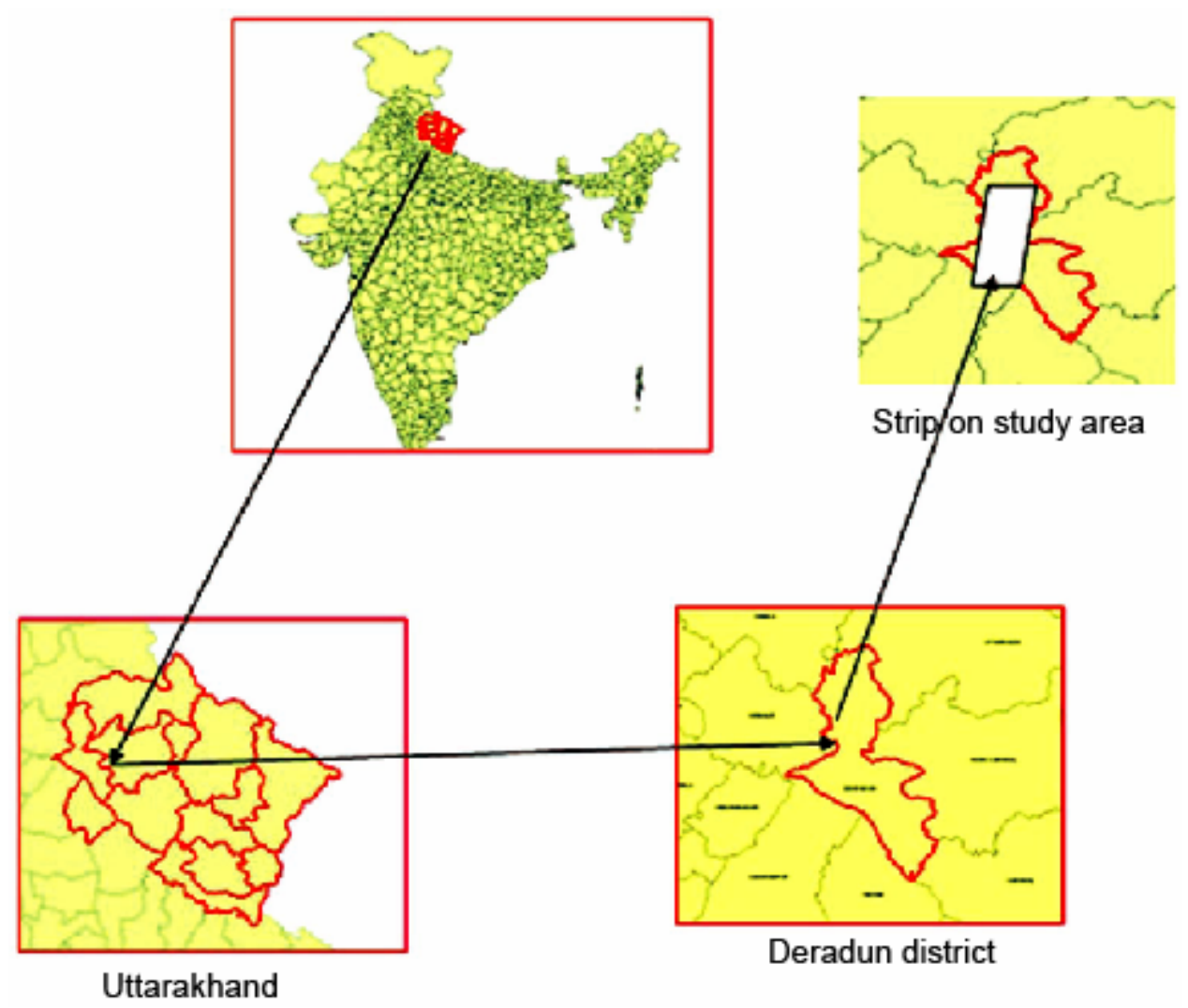

Fig. 1. Location of the study area.

The parameters used in the atmospheric correction model were radiance image, scene center location (30.34, 74.0066), sensor type (Hyperion), sensor altitude $(705 \mathrm{Km})$, flight time GMT(05:08:45), atmospheric model (tropical), aerosol model (urban), pixel size $(30 \mathrm{~m})$, ground elevation $(0.90 \mathrm{~km})$, water absorption features $(1135 \mathrm{~nm})$, initial visibility $(18 \mathrm{~km}), \mathrm{CO}_{2}$ mixing ratio (390), modtran resolution $\left(5 \mathrm{~cm}^{-1}\right)$, Zenith angle (180), Azimuth angle (0.0), the scale factor in the ASCII file format etc. Atmospheric correction model affects the spectral response of the earth surface feature. The removal of moisture and haze effect from the spectral response curve which results in the smoothening of spectra 
was the positive, visual and functional effect of the atmospheric correction (Fig. 2A, B). The reflectance properties of vegetation in the VNIR and SWIR part of the spectrum, and the chlorophyll absorption regions, dominated by the atmospheric absorption, are corrected by the model. The spectral range $1648 \mathrm{~nm}$ was showing greater reflectance in the atmospherically corrected image than the uncorrected one. The atmospheric corrections also increase the signal to noise ratio which is very less in the space born Hyperion hyperspectral data. After the atmospheric correction, the hyperion image was geometrically corrected by taking Landsat ETM+ as base in ENVI software environment (Fig. 2 a, b).

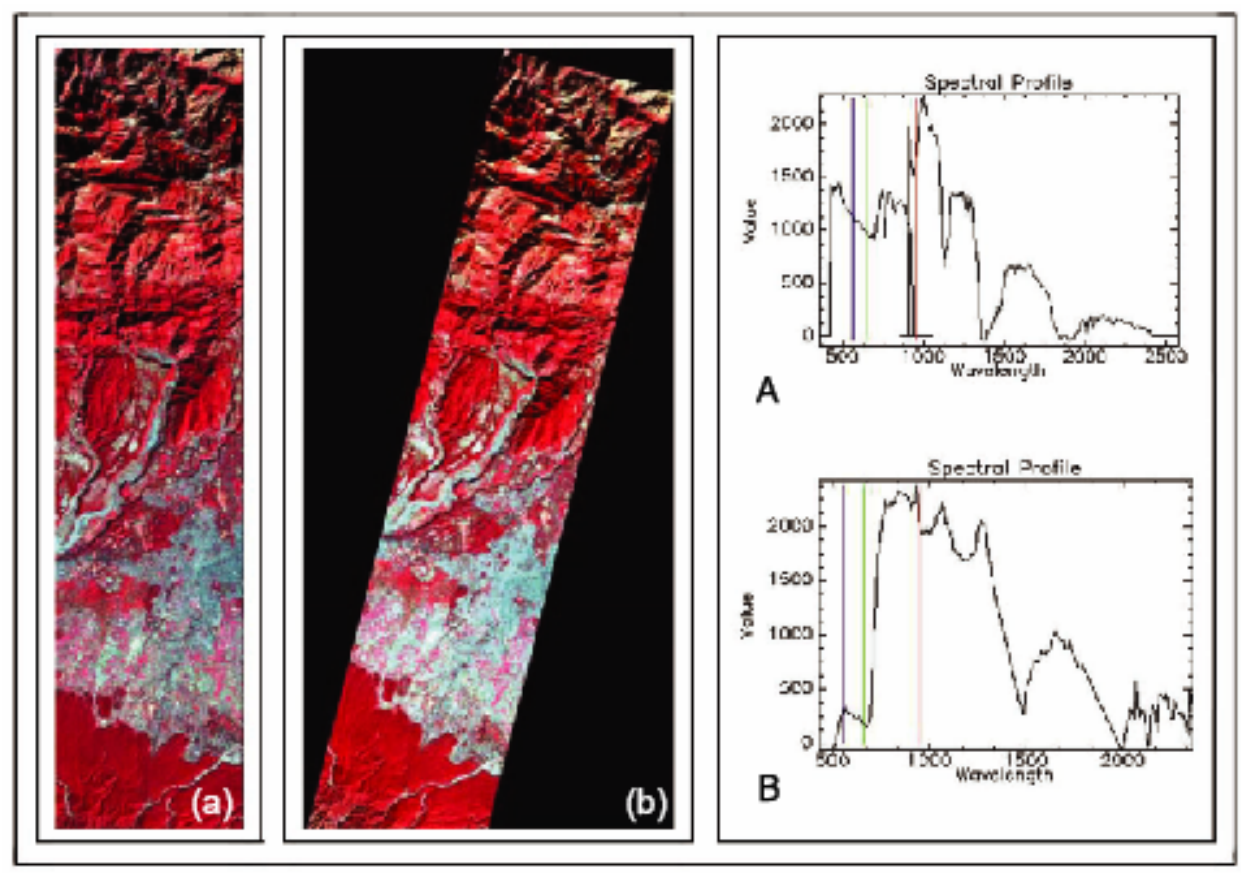

Fig. 2. Image and spectra before and after atmospheric correction. (a) FFC before georefrensing (b) FFC after georefrensing, A and B showing image spectra before and after atmospheric and geometric correction (wave length was in $\mathrm{nm}$ ).

Analytical spectral device (ASD spectroradiometer) with band range from 350 to $2500 \mathrm{~nm}$, collect information in 1251 bands at $2 \mathrm{~nm}$ band width was used to collect the species spectra in the field. The species spectra were saved in the ASD binary format. To compare the ASD field spectra with the atmospherically corrected Hyperion image spectra, the ASD spectra were resample to the Hyperion band width and a resample spectral library was created. The spectral resampling was done using ENVI software. All the resample spectra were separated in the three parts, (a) dominant species types observed on the ground, (b) partially distributed species, and (c) spectra generated from 
the Hyperion imagery. However, the SAM algorithm was run by using all the spectra together. Comparison of the resample field spectra of the species with the image spectra using spectral angle mapping algorithm, results in the species map of the study area. The resample spectral responses of different species were compared with each other to find the bands and ranges for the separation of species in the study area.

In spectral angle mapping (SAM) algorithm, classification was carried out through comparing image spectra to the spectra of individual endmember or reference spectra. A total of 14 endmember had been collected from the ground based ASD spectral responses and used in classifying the Hyperion data. However, three spectral signatures of the land use/cover i.e. settlement, barren land, and agriculture were collected from the Hyperion image directly. Standard angle threshold of 0.1 radians were used in classifying the satellite data except for the shadow area where it has been increased by 0.16 radians. The accuracy of SAM classification is assessed by a confusion matrix based on 66 independent field sample sites visited as reconnaissance survey of the study area.

Health of the Shorea robusta forest has been obtained from the atmospherically corrected hyperspectral data using Red Edge-Normalized difference vegetation Index (RE-NDVI) for greenness, carotenoid reflectance Index 1 (CRI1) for leaf pigment and water band index (WBI) for light use efficiency. These indices have been selected on the basis of results obtained from them. NDVI reduces the shadow effect and detect vegetation stress, carotenoid reflectance shows stressed, senescent, or dead leaves, and water band index shows concentration and status of water.

$$
\begin{aligned}
& \text { RE-NDVI= (Q750- Q705/ Q750+ Q705) (1) (20) } \\
& \text { CRI1 }=(1 / \text { Q510 })-(1 / \text { @550) } \\
& \mathrm{WBI}=\quad(\mathrm{Q} 900 / \mathrm{Q} 970)
\end{aligned}
$$

These three indices together provide forest health index in the ENVI software environment. The relative scale of forest health varies from 1 to 9 . The lower values indicate poorest health of vegetation and the higher values indicate healthiest vegetation.

\section{Results and Discussion}

On applying the spectral angle mapping classifier using ASD spectra collected from the field in ENVI software environment, different dominant species have been mapped (Fig. 3). These were Quercus leucotricophora A. Camus (banj oak), Shorea robusta Gaertn. f., Cedrus deodara Roxb. (cedar), Cupressus torulosa D. Don (Cypress), Thuja orientalis L., Lantana camara L., Bauhinia variegata Linn. (Benth.), Pinus roxburghii Roxb., Rhododendron arboreum Smith, (burans), Berberis vulgaris, Mallotus philippinensis, Cassia fistula and Acacia catechu. Agriculture, barren land and settlement were mapped using the image spectra. Simultaneously the main river course was also mapped with the manual effort to restrict the mixing between pixels of barren land and river course after the species mapping. 
Changes is the forest cover of Sundarbans mangrove forests ${ }^{(23)}$, changes in the mapping of spatial distribution of savannas plant species to maintain the biodiversity of these ecosystems $^{(24)}$, plant species richness and regional biodiversity hotspots ${ }^{(25)}$ have been studied successfully by using remote sensing and GIS techniques.

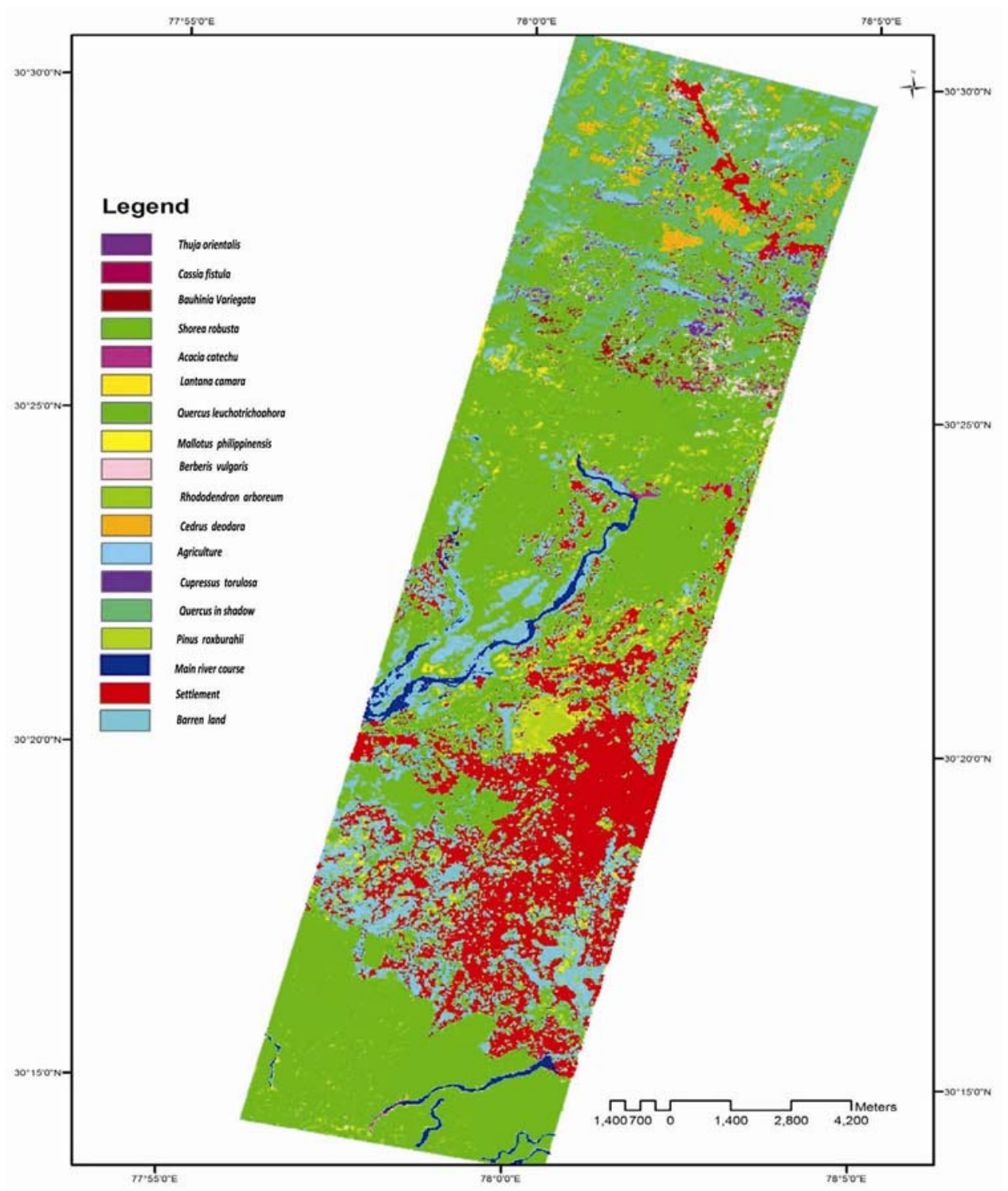

Fig. 3. Map of dominant tree species.

It was observed that the study area was dominated by the oak (Q. leucotrichophora), S. robusta, C. deodara, P. roxburghii and T. orientalis. In the temperate region Quercus spp. were dominant. At the elevation of 1200 - $1250 \mathrm{~m}$, the Quercus glauca species have been 
observed. Similarly Q. leucotrichophora (Ban Oak) at 2100 - $2150 \mathrm{~m}$, Quercus floribunda Lindl. Ex A. Camus (telonj) (Moru Oak) at 2400 - $2450 \mathrm{~m}$, and Quercus semicarpifolia Smith (Kharshu Oak) at an elevation of 3040 - $3050 \mathrm{~m}$, have been observed.

At the higher elevation of 2500 - $3000 \mathrm{~m}$ R. arboretum was present with the Quercus species. Shadow influenced spectral curve of the Quercus species was used to map shadow areas with the angle threshold of 0.16 radian. This was showing potential to classify the Quercus species in the shadow part. For the convenience of understanding all other unclassified shadow influenced pixels in the similar class were included and named it as Quercus in shadow. Cedrus deodara was observed at an elevation of about $2100-2300 \mathrm{~m}$ nearby Mussoorie on ground. The optical properties of the C. deodara leaf were showing the less reflectance in the VNIR and SWIR region due to its needle shape structure. Mostly $C$. deodara was growing well in the northern aspect of the study area which was coming in the shadow part of the Hyperion image and could not mapped properly.

In the tropical region major species were $S$. robusta and associated with $M$. philippensis, L. camara, Accasia catechu, Bauhinia variegata, Dalbergia sisso, Morraya quanigaii, Ficus bengalensis, Ficus religiosa, Terminalia tementosa, Syzygium cumini and Hypericum calycinum.

Thuja orientalis was present between the elevations of $600-1500 \mathrm{~m}$ and showing the characteristic tonal pattern of the subtropical forest type. The leaf optical response was showing less reflectance in the NIR region due to its compound structure. Cupressus torulosa species having similar leaf structure as T. orientalis was mapped with less accuracy and these were showing intermixing among the pixels. Acacia catechu was present nearby river course at lower elevation $(600-800 \mathrm{~m})$ and mapped properly. Other species were covering less area of the study site and forming understory of the dominant tree species were not mapped properly, however, the light loving species those were present outside the forest canopy were mapped for a few extent because of influence of the soil reflectance.

Due to less abundance and dominance of several other species present in this region, they were showing poor forest health, except a few viz. S. robusta, Quercus sp., L. camara, T. orientalis, C. deodara (Fig. 4). Good vigor (Forest health index value 7 - 9) has been seen in the S. robusta species. Similar result had been obtained in case of Quercus sp. Although the $L$. camara was distributed in large extent its health index was low (3 - 5) showing less leaf area index (LAI) and biomass as comparison to the dominant tree species. The mixed forests were showing medium to low health index values. To overcome the problem of mixing of species during the species mapping forest health index was applied which was very much effective in the identification of pure and mixed patches of $S$. robusta. It has been observed that the $S$. robusta mixed with L. camara has lower forest health index value (4 - 6) in comparison to the pure patch of S. robusta. This indicated interspecific 
competition of L. camara and S. robusta for the resources in mixed patches which largely affect the health of particular species. Forest vigor and health can be evaluated by using satellite-derived vegetation indices such as NDVI that can monitor large remote areas with an effective database(26).

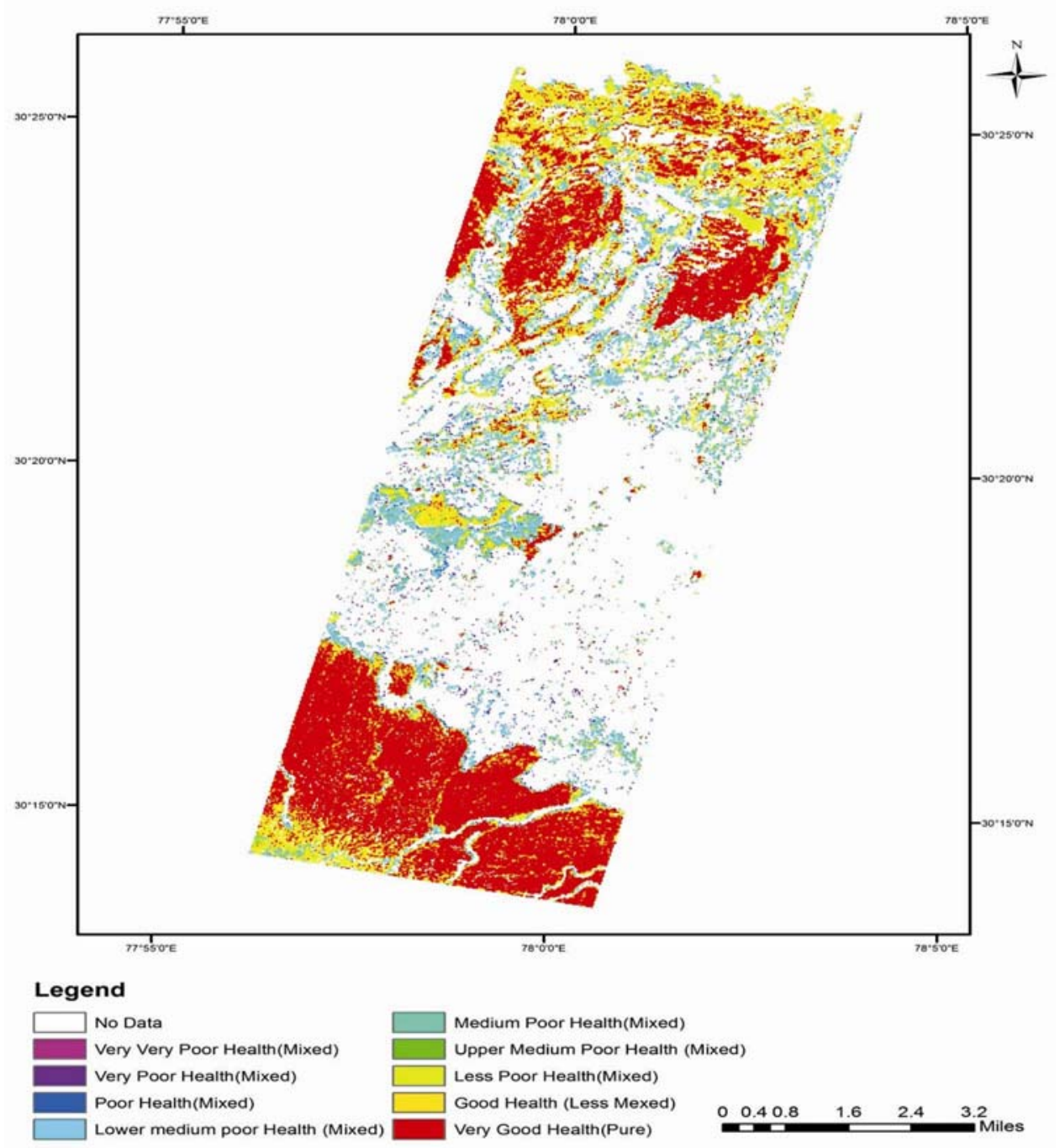

Fig. 4. Health distribution map of Shorea robusta as an indicator of pureness.

Higher index value (9) was showing pure patches while lower index values $(<8)$ were showing mixed patches (Fig. 4). About $48 \%$ area under the S. robusta species were showing pureness while $52 \%$ area was in the mixed form. Lantana camara was spread from lower elevation of tropical to higher elevation of lower temperate forest cover as an invasive species and largely impacting the health of S. robusta in the lower elevation. For 
the temperate region where the topography was very much undulating and creating shadow the health index was not calculated properly. However, Quercus spp. and C. deodara have been found pure from ground observation.

The accuracy of SAM based classification algorithm was assessed by a confusion matrix based on 66 independent field sample sites visited as reconnaissance survey of the study area. Fifty one points were found correct showing an overall accuracy of $77 \%$ with the Kappa coefficient of 0.75. Confusion matrix for that has been presented in Table 1.

Table 1. Confusion matrix (CM) of the accuracy of SAM based classification algorithm.

\begin{tabular}{llllllllllllllllllll}
\hline $\mathrm{CM}$ & 1 & 2 & 3 & 4 & 5 & 6 & 7 & 8 & 9 & 10 & 11 & 12 & 13 & 14 & 15 & 16 & 17 & 18 & 19 \\
\hline 1 & 2 & 1 & 0 & 0 & 0 & 0 & 1 & 0 & 0 & 0 & 0 & 0 & 0 & 0 & 0 & 0 & 0 & 0 & 4 \\
2 & 0 & 0 & 1 & 0 & 0 & 0 & 0 & 0 & 0 & 0 & 0 & 0 & 0 & 0 & 0 & 0 & 0 & 0 & 1 \\
3 & 0 & 0 & 2 & 0 & 1 & 0 & 0 & 0 & 0 & 0 & 0 & 0 & 0 & 0 & 0 & 0 & 0 & 0 & 3 \\
4 & 0 & 0 & 0 & 11 & 0 & 1 & 0 & 1 & 0 & 0 & 0 & 0 & 0 & 0 & 0 & 0 & 0 & 0 & 13 \\
5 & 0 & 0 & 0 & 0 & 2 & 0 & 0 & 0 & 0 & 0 & 0 & 0 & 0 & 0 & 0 & 0 & 0 & 0 & 2 \\
6 & 0 & 0 & 0 & 2 & 0 & 4 & 0 & 0 & 0 & 0 & 0 & 0 & 0 & 0 & 0 & 0 & 0 & 0 & 6 \\
7 & 0 & 0 & 0 & 0 & 0 & 0 & 8 & 0 & 1 & 0 & 0 & 0 & 0 & 0 & 0 & 0 & 0 & 0 & 9 \\
8 & 0 & 0 & 0 & 2 & 0 & 0 & 0 & 1 & 0 & 0 & 0 & 0 & 0 & 0 & 0 & 0 & 0 & 0 & 3 \\
9 & 0 & 0 & 0 & 0 & 0 & 0 & 0 & 0 & 1 & 0 & 0 & 0 & 0 & 0 & 0 & 0 & 0 & 0 & 1 \\
10 & 0 & 0 & 0 & 0 & 0 & 0 & 1 & 0 & 0 & 2 & 0 & 0 & 0 & 0 & 0 & 0 & 0 & 0 & 3 \\
11 & 0 & 0 & 0 & 0 & 0 & 0 & 0 & 0 & 0 & 0 & 3 & 0 & 0 & 1 & 0 & 0 & 0 & 0 & 4 \\
12 & 0 & 0 & 0 & 0 & 0 & 0 & 0 & 0 & 0 & 0 & 0 & 2 & 0 & 0 & 0 & 0 & 0 & 0 & 2 \\
13 & 0 & 0 & 0 & 0 & 0 & 0 & 0 & 0 & 0 & 0 & 0 & 0 & 1 & 0 & 0 & 0 & 0 & 0 & 1 \\
14 & 0 & 0 & 0 & 0 & 0 & 0 & 0 & 0 & 0 & 0 & 0 & 0 & 0 & 5 & 0 & 0 & 0 & 0 & 5 \\
15 & 0 & 0 & 0 & 0 & 0 & 0 & 0 & 0 & 0 & 0 & 1 & 0 & 0 & 0 & 2 & 0 & 0 & 0 & 3 \\
16 & 0 & 0 & 0 & 0 & 0 & 0 & 0 & 0 & 0 & 0 & 0 & 0 & 0 & 0 & 0 & 1 & 0 & 0 & 1 \\
17 & 0 & 0 & 0 & 0 & 0 & 0 & 0 & 0 & 0 & 0 & 0 & 0 & 0 & 0 & 0 & 0 & 1 & 0 & 1 \\
18 & 0 & 0 & 0 & 0 & 0 & 0 & 0 & 0 & 0 & 0 & 0 & 0 & 0 & 1 & 0 & 0 & 0 & 3 & 4 \\
19 & 2 & 1 & 3 & 15 & 3 & 5 & 10 & 2 & 2 & 2 & 4 & 2 & 1 & 7 & 2 & 1 & 1 & 3 & 66 \\
\hline
\end{tabular}

$1=$ Thuja orientalis, $2=$ Cassia fistula, $3=$ Bauhinia variegata, $4=$ Shorea robusta, $5=$ Acacia catechu, $6=$ Lantana camara, 7 = Quercus leuchotrichophora, $8=$ Mallotus philippinensis, $9=$ Berberis vulgaris, $10=$ Rhododendron arboreum, 11 = Cedrus deodara, 12 = Agriculture, $13=$ Cupressus torulosa, $14=$ Quercus in shadow (Including others), 15 = Pinus roxburghii, 16 = Main River course, $17=$ Settlement, $18=$ Barren land and $19=$ Total.

It is difficult to prepare a species level map from multispectral data using machine based classification approach, because of non-contiguity among the bands. This was feasible to be done using Hyperspectral data. Presently SAM algorithm had shown potential of species mapping with better accuracy $(77 \%)$ compared to the Vyas et al.(17) (66\%) in 2011.

In the present study continuous spectral signatures had been used for the discrimination and mapping of the species in the part of Mussoorie hills and lower 
Shiwalik Hills. The species map prepared using this approach could be used for the planning and management of the species to ensure their conservation and sustainable utilization. By applying SAM algorithm it was possible to map about 14 species with an overall accuracy (OAA) of $77 \%$ which was better than the earlier work ${ }^{(17)}$ for the tropical vegetation $(\mathrm{OAA}=66 \%)$. Martin et al. ${ }^{(27)}$ explored the capability of airborn Hyperspectral data in the discrimination of 11 species of Harvard forest with an accuracy of $75 \%$. SAM algorithm was not affected by the shadow that is why it would be good method of species mapping in the Hilly terrain. The species level map will help in the identification of the pure patches of the species with the help of forest health index, which can further be utilized for the conservation, planning, management, stratification for biomass sampling plot design and timber resource assessment. Forest resource assessment through Hyperspectral remote sensing enabled to obtain species level information which could be better estimate for the planning and management of these natural resources. Species level information related to the productivity would be beneficial in the understanding and comparison of carbon sequestration and its rate in different species ranging from temperate to sub-tropical to tropical region. Implementation of REDD+ strategy for the enhancement of carbon stock and reduction of the greenhouse gases a prime objective of the Kyoto protocol could also be achieved through this advanced technology. Planning sustainable utilization of forestry resources and modeling their future scenario are the recent trends in the application of these advanced technologies, and the species information could be the cornerstone for the above purposes.

\section{Acknowledgement}

Authors are grateful to Dr. P. S. Roy, former Director and Dr. Y.V.N. Krishna Murthi, Director, Indian Institute of Remote Sensing (IIRS), for providing their kind support and institutional facilities. Authors are also thankful to Dr. S.K. Saha, Group Director Earth Resources and System Studies Group, IIRS for ASD and laboratory facilities of Agriculture and Soils Department along with their kind suggestions.

\section{References}

1. Tromp M and GF Epema 1998. Spectral mixture analysis for mapping land degradation in semi-arid areas. Geologie en Mijnbouw 77(2): 153-160.

2. Murthy MSR, GS Pujar and A Giriraj 2006. Geoinformatics-based management of biodiversity from landscape to species scale - An Indian perspective. Curr. Sci.91: 1477-1485.

3. Lees BG and K Ritman 1991. Decision-tree and rule-induction approach to integration of remotely sensed and GIS data in mapping vegetation in disturbed or hilly environments. Environ. Manag. 15(6): 823-831.

4. Shoshany M 2000. Satellite remote sensing of natural Mediterranean vegetation: A review within an ecological context. Progress in Phys. Geogr. 24(2): 153-178. 
5. Curran PJ, JL Dungan and DL Peterson 2001. Estimating the foliar biochemical concentration of leaves with reflectance spectrometry, testing the Kokaly and Clark methodologies. Remote Sensing Environ. 76: 349- 359.

6. Weiss M and F Baret 1999. Evaluation of canopy biophysical variable retrieval performances from the accumulation of large Swath Satellite Data. Remote Sensing Environ. 70: 293-306.

7. Blackburn GA 1998. Quantifying chlorophylls and caroteniods at leaf and canopy scales: An evaluation of some hyperspectral approaches. Remote Sensing Environ. 66: 273-285.

8. Thenkabail PS, EA Enclona, MS Ashton, C Legg and DMJ De 2004. Hyperion, IKONOS, ALI and ETM+ sensors in the study of African rainforests. Remote Sensing Environ. 90: 23-43.

9. Walter H and W Koch 1980. Light reflectance characteristics of weed and crop leaves as effected by plant species and herbicides 1980 . British crop protection conference-weeds, pp. 243-250.

10. Pinet PC, C Kaufmann and J Hill 2006. Imaging spectroscopy of changing earth's surface: a major step toward the quantitative monitoring of land degradation and desertification. Comptes Rendus Geosci. 338(14-15): 1042-1048.

11. Nagendra H 2002. Using remote sensing to assess biodiversity. Int. J. Remote Sensing 22(12): 2377-2400.

12. Carter GA, KL Lucas, GA Blossom, CL Lassitterb, DM Holiday, DS Mooneyhan, DR Fastring, TR Holcombe and JA Griffith 2009. Remote sensing and mapping of Tamarix along the Colorado River, USA: A comparative use of summer-acquired hyperion, Thematic Mapper and QuickBird Data. J. Remote Sens. 1: 318-329.

13. Datt B 1999. Remote sensing of water content in Eucalyptus leaves. Aus. J. Bot. 47(6): 909 -923.

14. Skoupy O, L Zejdova and J Hanus 2012. The use of hyperspectral remote sensing for mapping the age composition of forest stands. J. For. Sci. 58: 287-297.

15. Omar H 2010. Commercial timber tree species identification using Multispectral Worldview2 Data, Digital Globe ${ }^{\circledR} 8$ Bands Res. Challenge pp. 2-13.

16. Dlamini WM 2010. Multispectral detection of invasive alien plants from very high resolution 8band satellite imagery using probabilistic graphical models, Digital Globe ${ }^{\circledR} 8$ Bands Research Challenge, pp. 1-17.

17. Vyas D, NSR Krishnayya, KR Manjunath, SS Ray and S Panigrahy 2011. Evaluation of classifiers for processing Hyperion (EO-1) data of tropical vegetation. Int. J. Appl. Earth Obser. Geoinfo. 13: 228-235.

18. Asner GP 1998. Biophysical and biochemical sources of variability in canopy reflectance. Remote Sensing Environ. 64(3): 234-253.

19. Vaiphasa C, S Ongsomwangc, T Vaiphasa and AK Skidmore 2005. Tropical mangrove species discrimination using hyperspectral data: a laboratory study. Estua., Costal and Shelf Sci. 65: 371-379.

20. Sims DA and JA Gamon 2002. Relationships between leaf pigment content and spectral reflectance across a wide range of species, leaf structures and developmental stages. Remote Sensing Environ. 81: 337-354.

21. Gitelson AA, Y Zur, OB Chivkunova and MN Merzlyak 2002. Assessing carotenoid content in plant leaves with reflectance spectroscopy. Photochem. and Photobiol. 75: 272-281. 
22. Penuelas J, I Filella, C Biel, L Serrano and R Save 1995. The reflectance at the 950-970 region as an indicator of plant water status. Int. J. Remote Sens. 14:1887-1905.

23. Chaffey DT, FR Miller and JH Sandom 1985. A forest inventory of the Sundarbans, Bangladesh. Project Report 140. Fig. 1a-1i. Land Resource Development Centre. Toluorth Tower, Surbitan, Surrey. England KT6 7DY.

24. Colgan MS, CA Baldeck, Jean-Baptiste Féret and GP Asner 2012. Mapping savanna tree species at ecosystem scales using support vector machine classification and BRDF correction on airborne hyperspectral and LiDAR data. Remote Sens. 4: 3462-3480.

25. Gould W 2000. Remote sensing of vegetation, plant species richness and regional biodiversity hotspots. Ecol. Applic. 10: 1861-1870.

26. Wang J, TW Sammis and VP Gutschick 2010. Review of satellite remote sensing use in forest health studies. The Open Geo. J. 3: 28-42.

27. Martin ME, SD Newman, JD Aber and RG Congalton 1998. Determining forest species composition using high spectral resolution remote sensing data. Remote Sensing Environ. 65: 249-254.

(Manuscript received on 5 December, 2013; revised on 19 March, 2014) 